without whom nothing can be done, the men whom we all admire so much that we almost forget their faults-I ask them to translate our poor ideas, our platitudes, our truisms, our copy-book maxims as to what ought to be done, into actual performance. The wonderful papers or books that they are now writing, can these make their names glorious for more than fifty or a hundred or a few hundreds of years? Is this fame to be weighed against the greater reward we offer? They have the chance of causing mathematics to be made a mental tool always ready for use by the engineer and physicist, the pioneers of thought and civilisation in this stage of the world's history. We ask them to take a high view of the value of their opportunities; really to lead the vanguard in the attack now at last being organised against the general ignorance of our people.

Let them think of all the university colleges and engineering schools of the country, and consider how disgust at useless routine has led to general neglect of duty in teacher and taught. I know of a college where two senior wranglers in succession have taken charge of the education of the average student, and there has been no teaching of mathematics for many years. I know of another college where another senior wrangler does his best to maintain the old tradition that a man paid to teach ought to know nothing of teaching, ought to care nothing for teaching, and ought to feel insulted if the persons who pay him his salary happen to mention efficiency of teaching in his presence. I acknowledge that these professors are of the salt of the earth; they have done great service to science by their own work; they ought to be encouraged to do more and more of the work that they are specially fitted to perform, but $I$ do say that it is a shame to sacrifice all their students because it happens that Cambridge has not enough endowment for such men. Fifty years ago it did not matter to us if 90 per cent. of the undergraduates at Cambridge made fun of mathematics. It matters to us now very much indeed that the most important weapon that any modern nation can have, the power to compute, should be jeered at by the very men, the engineers, who could make most use of it if they only knew how. This is my excuse for what seems a great presumption in criticising Cambridge and in asking that my ideas shall have a careful consideration. I want to see schemes drawn up for the education of all kinds of civil and military engineers. The courses of study must be made interesting and useful. I do not wish to find that a sailor who has worked out all Napier's and Gauss's analogies has never measured a distance with a tape line on a terrestrial globe, or that he cannot do " the day's work," as it is called, without using seven or six figure logarithms.

It is surely an awful thing that many earnest men, because they have faith in us, should be induced to spend years in making ropes of sand. At the end of long academic courses an examiner finds the best students to be quite satisfied with sand-rope making, and mathematics will be as much detached from their professional work as the game of patience is detached from the daily avocation of the lady who plays it. As for the average men who hate the whole thing, they are better off ; I mean, of course, if they manage to pass their examinations, for they can look before and after, and need not pine for what they never nad.

The nation feels that its common sense has been outraged, and it is not merely elementary education that is going into the melting-pot. Is Cambridge going to hold aloof from the little army of men who think that the melting and solidifying processes need to be guided? Has Cambridge no interest whatsoever in the nature of the possible crystallisation?

There is no great engineering school the mathematics of which ought not to be in charge of as fine a mathematician as a salary of $1500 l$. or $2000 l$. a year can tempt; is this man to be a Cambridge man?

Let Cambridge make no mistake as to the issue now before us. We know she can do what we want if she likes to set herself to it, and we are willing to coax her, for we owe her much. We shall take care that her very highest ideals are not interfered with; if she makes mathematics popular, pleasant and useful to practical people, she will receive back again such great pupils in pure and applied mathematics as she does not dream of now.

JOHN PERRY.
Radio-activity of Ordinary Materials.

IN connection with Mr. Strutt's article on this subject in this week's NATURE, I may mention that I have received for publication from Prof. McClennam and Mr. Burton, of the University of Toronto, the manuscript of a paper read before the American Physical Society in December last, on the saturation current in cylinders of the same size but of different materials. The cylinders used were $25 \mathrm{~cm}$. in diameter, and were made of zinc, tin and lead; the current in the lead cylinder was about twice that in the zinc, and about 50 per cent. greater than in the tin. The authors found that the current in the cylinders was considerably reduced by immersing the cylinders in a large cistern full of water, indicating that part of the ionisation is due to very penetrating radiation which gets through the sides of the cylinder. I may take this opportunity of stating that I have found that lead apparently gives off an emanation similar to that emitted by radium, for if lead acetate or lead nitrate be dissolved in distilled water, and air very slowly bubbled through the solution, the air coming out has greater conductivity than if it had been bubbled through the distilled water alone, and it retains this additional conductivity for many hours. We hope to investigate the effect of other metals in solutions and to determine whether or not it is due to the radio-active impurities in the salts.

J. J. ThOMson.

Cavendish Laboratory, Cambridge, February 21.

\section{Fall of Coloured Dust on February 22-23.}

I HAVE received this morning from two of the observers of the Royal Meteorological Society samples of red or muddy rain which fell on Sunday night or Monday morning.

Mr. C. Grover, of the Rousdon Observatory, Devon, on Monday morning, February 23, found that the windward sides of the thermometer screens were conspicuously marked with a deposit of reddish or rusty coloured mud, so thick as to attract attention at once. There was the same appearance on the anemometer tower-the window ledges, the iron ladder and the white painted wooden shelf thirty feet above the ground being all marked with the same deposit. The rainfall was only $0^{\circ} \mathrm{O} 2$ inch.

Mr. J. W. Phillips, of Haverfordwest, says that rain fell between 6 and $9 \mathrm{a} \cdot \mathrm{m}$. on Monday, and that when the rain gauge was examined the water was found to have a sediment of dust. The quantity of rain measured was $0^{\circ} 3 \mathbf{I}$ inch. Mr. Phillips says that the phenomenon has been noticed in other parts of the country.

The deposit at Rousdon was apparently much thicker than at Haverfordwest The fall must have extended over a wide area.

WM. MARRIOTT.

Royal Meteorological Society, S.W., February 24.

\section{Chapman's Zebra.}

In the course of some studies of the genus Equus, I obtained a number of measurements of the skulls of zebras and quaggas through the kindness of Mr. J. A. G. Rehn. The measurements were based on specimens contained in the collection of the Philadelphia Academy of Natural Sciences. Upon comparing these data, I found that the measurements for Equis chapmani did not approach most nearly those of $E$. burchelli, of which chapmani is supposed to be a variety. Roughly speaking, if the resemblance to burchelli were expressed by 4 , that to $E$. zebra would be expressed by 6 , that to $E$. grevyi by 3 , and that to $E$. quagga by I. ${ }^{1}$ In particular, E. sebra and chapmani had the zygomatic breadth and the breadth between the orbits above much less than in burchelli. The specimen of chapmani was said to be from Zanzibar. Part of the facts observed may be due to immaturity, and Mr. Oldfield Thomas warns me that the precise identification of $E$. chapmani is a matter of doubt; but from what I have been able to learn, it seems not impossible that $E$. chapmani, as represented by Prof. Ewart's "Matopo," may be a valid species. As it is quite out of the question for me to settle this matter, I venture to commend it to such of your readers as have better opportunities.

East Las Vegas, N.M., U.S.A., January 23

$$
\text { T. D. A. Cockerell. }
$$

3 These figures are based, not on the absolute measurements, but on the measurements expressed in percentages of the total length of the skull. 